\title{
Risk factors of frailty and death or only frailty after intensive care in non-frail elderly patients: a prospective non- interventional study
}

Yoann Launey ${ }^{1}$, Hervé Jacquet ${ }^{1}$, Matthieu Arnouat ${ }^{1}$, Chloe Rousseau ${ }^{2}$, Nicolas Nesseler ${ }^{1,3}$ and Philippe Seguin ${ }^{1,2,3,4^{*}}$ (D)

\begin{abstract}
Background: Frailty status is recognized as an important parameter in critically ill elderly patients, but nothing is known about outcomes in non-frail patients regarding the development of frailty or frailty and death after intensive care. The aim of this study was to determine risk factors for frailty and death or only frailty 6 months after intensive care unit (ICU) admission in non-frail patients $\geq 65$ years.

Methods: A prospective non-interventional study performed in an academic ICU from February 2015 to February 2016 included non-frail $\geq 65$-year-old patients hospitalized for $>24 \mathrm{~h}$ in the ICU. Frailty was assessed by calculating the frailty index $(F I)$ at admission and 6 months later. Patients who remained non-frail $(F I<0.2)$ were compared to patients who presented frailty $(F I \geq 0.2)$ and those who presented frailty and death at 6 months.

Results: Among 974 admissions, 136 patients were eligible for the study and 88 patients were analysed at 6 months (non-frail $n=34$, frail $n=29$, death $n=25$ ). Multivariable analysis showed that mechanical ventilation duration was an independent risk factor for frailty/death at 6 months (per day of mechanical ventilation, odds ratio $[\mathrm{OR}]=1.11 ; 95 \%$ confidence interval $[\mathrm{Cl}] 1.04-1.19, p=0.002$ ). When excluding patients who died, mechanical ventilation duration remained the sole risk factor for frailty at 6 months $(\mathrm{OR}=1.19 ; 95 \% \mathrm{Cl} 1.07-1.33, p=0.001)$.

Conclusion: Mechanical ventilation duration was the sole predictive factor of frailty and death or only frailty 6 months after ICU hospitalization in initially non-frail patients.
\end{abstract}

Keywords: Critical care, Non-frail, Elderly, Outcome

\section{Introduction}

As life expectancy increases, the need for hospitalization in the general ward and the intensive care of elderly patients is increasing, representing a major challenge over the next few years in an increasingly financially constrained system [1-4]. Faced with this demographic challenge, it is now well accepted that age itself is not relevant for intensive care unit (ICU) admission decisions and that other parameters must be taken into account, notably, comorbidities

\footnotetext{
* Correspondence: philippe.seguin@chu-rennes.fr

${ }^{1} \mathrm{CHU}$ Rennes, Université Rennes 1, Service de Réanimation Chirurgicale,

Hôpital Pontchaillou, 2 rue Henri Le Guilloux, 35033 Rennes Cedex 9, France

${ }^{2} \mathrm{CHU}$ de Rennes, Centre d'Investigation Clinique, Inserm 1414, 2 rue Henri Le

Guilloux, 35033 Rennes Cedex 9, France

Full list of author information is available at the end of the article
}

and functional status [5]. Frailty, a geriatric concept developed at the end of the last century in the USA and Canada, is defined as a decrease in physiological reserves inducing an alteration in the mechanisms of adaptation to stress [6]. There is now clear evidence that frail elderly patients hospitalized in ICUs are at particular risk of early complications, long-term disabilities and death, independent of age and usual severity markers [7-12]. Additionally, some patients considered non-frail at admission will become frail or will die after ICU hospitalization. To the best of our knowledge, no study has evaluated the factors that contribute to a non-frail patient at admission becoming frail and dying or becoming frail after ICU hospitalization.

(c) The Author(s). 2019 Open Access This article is distributed under the terms of the Creative Commons Attribution 4.0 International License (http://creativecommons.org/licenses/by/4.0/), which permits unrestricted use, distribution, and 
In this context, the objective of this study was to determine the risk factors for becoming frail and dying or becoming frail 6 months after ICU hospitalization in initially non-frail patients older than 65 years.

\section{Patients and methods}

This was a prospective, non-interventional study conducted from February 2015 to February 2016 in the ICU of the University Hospital of Rennes. Within this period, all patients aged 65 years or older admitted to intensive care for $>24 \mathrm{~h}$ and whose frailty index (FI) was $<0.2$ were eligible. Patients who were unable to answer questions, under curatorship and/or for whom no relatives were present or able to answer questions were excluded. During the period of study, only the first admission was considered. The protocol was approved by the Ethics Committee of the University Hospital of Rennes. Institutional review board waived written informed consent according to the no-interventional study design.

The main objective was to compare the initially nonfrail patients admitted to the ICU who remained nonfrail at 6 months with those who developed frailty and/ or died at 6 months. In addition, the probability of developing moderate or severe frailty or dying was assessed.

\section{Frailty assessment}

Frailty was assessed by measuring the FI [13]. This measurement was based on an interview with the patient (or relatives if the patient was unable to answer questions) using a previously validated 40-item questionnaire; 6 items (minimental state examination, grip strength, shoulder strength, peak flow, usual pace and walking pace) were removed because they could not be measured in ICU patients, and heart attack was associated with chronic heart failure [13]. Accordingly, a total of 33 items, including different domains related to health status, were explored (see Additional file 1), and questions focused on autonomy for activities of daily living, physical and emotional health, the presence of chronic condition(s), cognition, nutritional status and objective respiratory parameters (Additional file 1). Each item was assigned a point value ranging from 0 (not at all altered) to 1 (completely altered). The FI was obtained by dividing the number of points by the number of items evaluated. For example, if the total points were 10 out of 30 items for which a response could be obtained, the FI was 0.33 (10/30). This score ranged from 0 to 1 , and frailty was defined as an $\mathrm{FI} \geq$ 0.2 [13]. A response for at least 30 variables was recommended for an FI calculation [13]. The interview was conducted during the first $72 \mathrm{~h}$ of ICU hospitalization by 2 ICU physicians. Only patients with an $\mathrm{FI}<0.2$ at admission were included. The FI was measured again at 6 months, and patients who remained non-frail $(\mathrm{FI}<0.2)$ were compared to those who developed frailty and died, and those who developed only frailty. At 6 months, frailty was assessed by phone by the same $2 \mathrm{ICU}$ physicians using the same questionnaire administered at admission.

\section{Data collection}

The following data were collected: age, sex, body mass index, marital status, usual place of residence, ICU hospitalization in the 6 months preceding the current hospitalization and reason for admission (medical, trauma or unscheduled or scheduled surgery). Severity was assessed by the severity acute physiologic assessment II (SAPS II) and by the Sequential Organ Failure Assessment (SOFA) scores $[14,15]$. Life expectancy was estimated by the McCabe score [16]. The activity of daily living was assessed by the Katz index and comorbidities were assessed by the Charlson index $[17,18]$. The following clinical data at admission were also noted: shock and, if present, the type of shock; infection and, if present, the site of infection; and the severity of infection (sepsis or septic shock) and bacteraemia.

During the entire ICU hospitalization period, the following data were also collected: use of vasopressor and the maximal dose, the presence of acute respiratory distress syndrome according to the Berlin definition [19], the occurrence of acute renal failure according to the risk, injury, failure, loss, and end-stage renal failure (RIFLE) score [20]; the maximum level of plasmatic creatinine observed; the use of extra-renal replacement therapy; and the need and duration of mechanical ventilation. Sedation and its duration were also noted, as well as the mean doses of sedative agents $(\mathrm{mg} / \mathrm{h})$ and the use of neuro-muscular blocking agents. The administration of enteral nutrition and the mean $\mathrm{Kcal} / \mathrm{kg} \mathrm{day}^{-1}$ for days 0 to 5 and 6 to 10 were also recorded as well as the dose of protein administered in $\mathrm{g} / \mathrm{kg} \mathrm{day}^{-1}$ for days 0 to 5 and 6 to 10. The acquisition of infection during ICU hospitalization, its severity and the number of acquired infections were noted. Finally, mobilization and out of bed were notified and reported as at least one action once during ICU stay.

The ICU and hospital length of stay, the decision to withdraw or withhold life-sustaining therapies during the ICU stay and mortality were reported.

\section{Statistical analyses}

The statistical analyses were performed using SAS software version 9.4 (SAS Institute, Cary, NC). The quantitative variables were reported as the median (interquartile range 25-75) and compared by non-parametric MannWhitney Wilcoxon tests, and the qualitative variables were reported as $n$ (percentage) and compared by $\chi^{2}$ or nonparametric Fisher's tests as required. Patients who remained non-frail at 6 months were compared to patients who developed frailty and died, and the analysis was extended to patients who survived but developed frailty at 6 months. A $p$ value $<0.05$ was considered statistically 
significant. The risk factors for frailty and death and only frailty at 6 months were then tested by logistic regression. Significantly clinically relevant parameters in univariate analysis at $p<0.20$ were included in a multivariate model, and a stepwise top-down selection was performed.

\section{Results}

During the study period, a total of 974 patients were admitted to the ICU and 89 patients $\geq 65$ years old were non-frail at admission $(\mathrm{FI}<0.2)$ (Fig. 1). One patient was lost before follow-up at 6 months and was therefore excluded from the analysis. Accordingly, a total of 88 patients were analysed: 34 remained non-frail at 6 months and 54 developed frailty or died (frail $n=29$ and dead $n=25$ ) at 6 months.

When we compared patients who remained non-frail at 6 months to those who developed frailty or died at 6 months, the baseline characteristics and clinical data at admission of the two groups were comparable; however, patients who developed frailty or died at 6 months were significantly more likely to have been hospitalized in the 6 months prior to inclusion (Tables 1 and 2). Clinical data recorded during the entire ICU hospitalization and data related to the occurrence of infection during ICU hospitalization but not present at admission are reported in Tables 3 and 4, respectively. The durations of mechanical ventilation and sedation were significantly higher in patients who developed frailty or died, and patients who remained non-frail received significantly less Kcal/ $\mathrm{kg} \mathrm{day}^{-1}$ and less protein $\left(\mathrm{g} / \mathrm{kg} \mathrm{d}^{-1}\right)$ via enteral nutrition during the first 5 days of hospitalization. The ICU and hospital length of stay, withdrawal or withholding of lifesustaining therapies in the ICU and the ICU, hospital and 6-month mortalities are presented in Table 5. The ICU and hospital lengths of stay were significantly longer in the group of patients who developed frailty or died at 6 months. The following variables were included in the multivariable analysis model: age, hospitalization during the 6 months preceding the current hospitalization, the Charlson index, infection during the current ICU stay, mechanical ventilation duration, mean daily dose of enteral nutrition between days 0 and 5 and hospital length of stay. After stepwise downward selection, only the duration of mechanical ventilation was an independent risk factor for progression to frailty/death at 6 months (per day of mechanical ventilation, odds ratio $[\mathrm{OR}]=1.11 ; 95 \%$ confidence interval $[\mathrm{CI}] 1.04-1.20, p=0.002$ ).

When we excluded patients who died and compared patients who remained non-frail with those who developed frailty at 6 months, the univariate analysis revealed the same data to be significant, except for the duration of sedation, which did not differ between the two groups (Tables $1,2,3,4$ and 5). The following variables were included in the multivariate analysis model: SOFA, ICU stay in the 6 months preceding the current hospitalization, duration of mechanical ventilation, mean daily enteral nutrition between days 0 and 5 and hospital length of stay. Similarly, only the duration of mechanical ventilation was found to be a risk factor for frailty at 6 months (per day of mechanical ventilation, $\mathrm{OR}=1.19 ; 95 \%$ CI 1.07-1.33, $p=0.001$ ).

The details of the items included in the questionnaire are provided in Additional file 2. In patients who were non-frail at admission but developed frailty at 6 months, the primary difficulties reported by the patients at 6 months were related to basic and instrumental daily

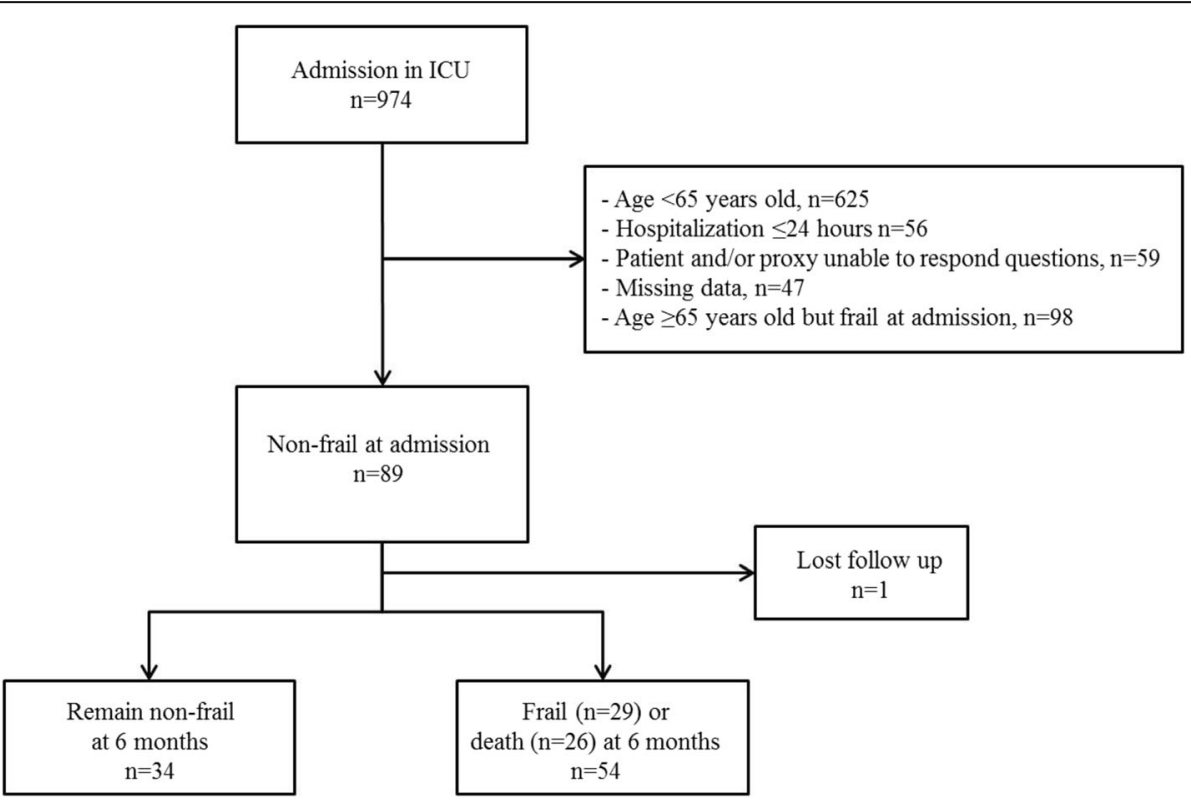

Fig. 1 Flow chart 
Table 1 Baseline characteristics of patients remaining non-frail vs those who developed frailty and died and those who developed only frailty

\begin{tabular}{|c|c|c|c|c|c|}
\hline & Non-frail at 6 months $(n=34)$ & Frail or death at 6 months $(n=54)$ & $P^{*}$ & Frail at 6 months $(n=29)$ & $P^{* *}$ \\
\hline Age, years & $71(66-77)$ & $75(68-81)$ & 0.102 & $73(68-77)$ & 0.403 \\
\hline Sex, male & $22(65)$ & $33(61)$ & 0.734 & $19(66)$ & 0.946 \\
\hline Body mass index, $\mathrm{Kg} / \mathrm{m}^{2}$ & $28(25-29)$ & $27(24-28)$ & 0.278 & $27(24-30)$ & 0.267 \\
\hline Married or common law & $23(82)$ & $31(70)$ & 0.264 & $31(69)$ & 0.210 \\
\hline Residence & & & 1.000 & $29(100)$ & 1.000 \\
\hline Living at home & $34(100)$ & $53(98)$ & & $0(-)$ & - \\
\hline Nursing home & $0(-)$ & $1(2)$ & & & \\
\hline Previous (6 months) ICU stay & $2(6)$ & $15(28)$ & 0.011 & $8(28)$ & 0.035 \\
\hline Type of admission & & & 0.321 & & 0.559 \\
\hline Unscheduled surgery & $12(35)$ & $25(46)$ & & $14(48)$ & \\
\hline Scheduled surgery & $7(21)$ & $10(18)$ & & $5(17)$ & \\
\hline Medical & $9(26)$ & $16(30)$ & & $8(28)$ & \\
\hline Trauma & $6(18)$ & $3(6)$ & & $2(7)$ & \\
\hline SAPS ॥ & $43(34-54)$ & $44(36-54)$ & 0.693 & $39(35-50)$ & 0.396 \\
\hline SOFA & $6(3-9)$ & $5(4-9)$ & 0.711 & $4(3-7)$ & 0.176 \\
\hline Mac Cabe & & & 0.455 & & 1.00 \\
\hline A & $25(73)$ & $32(59)$ & & $21(73)$ & \\
\hline B & $7(21)$ & $16(30)$ & & $7(24)$ & \\
\hline C & $2(6)$ & $6(11)$ & & $1(3)$ & \\
\hline Frailty index at admission, mean $\pm S D$ & $0.08 \pm 0.06$ & $0.10 \pm 0.05$ & 0.074 & $0.10 \pm 0.06$ & 0.119 \\
\hline Katz score & $6(6-6)$ & $6(6-6)$ & 1.000 & $6(6-6)$ & - \\
\hline Charlson score & $1(0-2)$ & $1(0-2)$ & 0.121 & $1(0-2)$ & 0.466 \\
\hline
\end{tabular}

Data are expressed as median (interquartile range $25-75$ ) and number (percentage) or otherwise mentioned. *Non-frail vs frail or died at 6 months. ${ }^{*}$ Non-frail vs frail at 6 months. SAPS // severity acute physiologic assessment II, SOFA Sequential Organ Failure Assessment

living activities, mobility, strength and changes in health status.

\section{Discussion}

To the best of our knowledge, this prospective noninterventional study is the first to investigate the risk factors for developing frailty and dying or developing only frailty 6 months after ICU hospitalization in elderly patients initially considered non-frail at admission. It appeared that the initial clinical data, notably, usual severity factors (SAPS II, SOFA), did not differ between the groups, suggesting that the occurrence of event(s) during the ICU stay rather than existing elements at admission were "tipping" factors in progressing from a non-frail to a frail status or death. In the multivariable analysis, only the duration of mechanical ventilation was an independent predictor of progression to frailty and death or only frailty in initially non-frail patients. Accordingly, it may be hypothesized that mechanical ventilation affects such a progression, but the mechanism for this progression needs further discussion.

From this perspective, hypomobility may be an important parameter to consider. Indeed, it has been shown that patients under mechanical ventilation are more prone to bed rest and less mobility. In a single-day study conducted in 38 Australian and New Zealand ICUs, out-of-bed activity was never practised in mechanically ventilated patients [21]. In a 1-day prevalence study performed in 116 ICUs in Germany with 783 mechanically ventilated patients, out-of-bed mobilization was reported in $24 \%$ of patients and only $4 \%$ could stand, march or walk [22]. In Switzerland, a 1-day prevalence study conducted in 35 ICUs showed that 33\% (53/191) of mechanically ventilated patients practised active mobilization, and walking was achieved in only $2 \%$ of patients [23]. In a 2-day crosssectional point prevalence study performed in 42 ICUs with patients who had acute respiratory failure requiring mechanical ventilation $>48 \mathrm{~h}$ at any point during their ICU stay, out-of-bed mobility was achieved on $16 \%$ of the total patient-days in mechanically ventilated patients and walking was achieved in only $4 \%$ of patients [24]. In contrast, non-mechanically ventilated patients spent $46 \%$ of patient-days out of bed. In this study, mechanical ventilation through the endotracheal tube or a tracheostomy and delirium were negatively associated with out-of-bed mobility [24]. The impact of bed rest and hypomobility on 
Table 2 Clinical data at admission for patients remaining non-frail vs those who developed frailty and died and those who developed only frailty

\begin{tabular}{|c|c|c|c|c|c|}
\hline & Non-frail at 6 months $(n=34)$ & Frail or death at 6 months $(n=54)$ & $P^{*}$ & Frail at 6 months $(n=29)$ & $P^{* *}$ \\
\hline Shock & $15(44)$ & $23(43)$ & 0.888 & $11(38)$ & 0.619 \\
\hline Type of shock & & & 0.076 & & 0.072 \\
\hline Septic & $9(60)$ & $10(48)$ & & $5(45)$ & \\
\hline Cardiogenic & $3(20)$ & $1(4)$ & & $0(-)$ & \\
\hline Hypovolemic & $2(13)$ & $10(44)$ & & $6(54)$ & \\
\hline Haemorrhagic & $0(-)$ & $1(4)$ & & $0(-)$ & \\
\hline Others & $1(7)$ & $0(-)$ & & $0(-)$ & \\
\hline Infection & $12(35)$ & $18(35)$ & 0.850 & $9(31)$ & 0.721 \\
\hline Site of infection & & & 0.871 & & 0.661 \\
\hline Abdominal & $4(33)$ & $5(28)$ & & $1(11)$ & \\
\hline Urinary & $2(17)$ & $3(17)$ & & $2(22)$ & \\
\hline Pulmonary & $1(8)$ & $4(22)$ & & $2(22)$ & \\
\hline Mediastinal & $2(17)$ & $4(22)$ & & $3(33)$ & \\
\hline Others & $3(25)$ & $2(11)$ & & $1(11)$ & \\
\hline Bacteraemia & $3(27)$ & $2(11)$ & 0.339 & $1(11)$ & 0.591 \\
\hline Infection severity & & & 0.645 & & 0.676 \\
\hline Sepsis & $1(8)$ & $3(17)$ & & $2(22)$ & \\
\hline Severe sepsis & $2(17)$ & $5(28)$ & & $2(22)$ & \\
\hline Septic shock & $9(75)$ & $10(55)$ & & $5(56)$ & \\
\hline
\end{tabular}

Data are expressed as number (percentage). *Non-frail vs frail or died at 6 months. ${ }^{* *}$ Non-frail vs frail at 6 months

muscle loss is well described, and elderly people are more prone to bed rest than younger people $[25,26]$. For 12 healthy old people remaining in bed for 10 days, it was shown that there was a significant decrease in muscle protein synthesis, whole-body lean mass and strength [25]. Moreover, after 14 days of bed rest, the muscle mass and function were significantly more altered in elderly people (age 55-65 years) than in younger people (age 18-30 years), and the application of a rehabilitation protocol after bed rest did not allow the recovery of the pre-bed rest conditions [26]. In the ICU, the bed rest duration was found to be an independent risk factor for muscle weakness in surviving acute respiratory distress syndrome (ARDS) patients [27, 28]. Clearly, ICU-acquired weakness is multifactorial and not exclusively related to bed rest [29]. Nevertheless, in our study, we did not find a difference between groups for the usual factors of ICU- acquired weakness, i.e. age and sepsis (at admission and during hospital stay); only the duration of mechanical ventilation was independently associated with subsequent frailty or frailty and death. At 6 months, we found that patients who developed frailty had, in comparison with nonfrail patients, strong deficits in mobility and strength and had more disabilities in daily living activities and instrumental activities that indirectly reflected the capacity to move (Additional file 2: Figure S1 and S2). The impact of hypomobility on functional capacity was explored in a randomized study comparing standard care to early physical/occupational therapy in patients mechanically ventilated for less than $72 \mathrm{~h}$. In this study, patients in the interventional group were able to walk a greater distance at hospital discharge than the control group and were more independent in daily living activities [30]. Nevertheless, the impact of physical/occupational therapy on

Table 3 Infection occurring during ICU hospitalization not present at admission

\begin{tabular}{|c|c|c|c|c|c|}
\hline & Non-frail at 6 months $(n=34)$ & Frail or death at 6 months $(n=54)$ & $P^{*}$ & Frail at 6 months $(n=29)$ & $P^{* *}$ \\
\hline Infection, yes & $4(12)$ & $16(30)$ & 0.051 & $7(24)$ & 0.197 \\
\hline Infection severity & & & 0.249 & & 0.524 \\
\hline Sepsis & $3(75)$ & $3(23)$ & & $3(43)$ & \\
\hline Severe sepsis & $0(-)$ & $3(23)$ & & $0(-)$ & \\
\hline Septic shock & $1(25)$ & $7(54)$ & & $4(57)$ & \\
\hline
\end{tabular}

Data are expressed as number (percentage). *Non-frail vs frail or died at 6 months. **Non-frail vs frail at 6 months 
Table 4 Clinical data during the entire hospitalization in ICU

\begin{tabular}{|c|c|c|c|c|c|}
\hline & Non-frail at 6 months $(n=34)$ & Frail or death at 6 months $(n=54)$ & $P^{*}$ & Frail at 6 months $(n=29)$ & $P^{* *}$ \\
\hline Norepinephrine, yes & $17(49)$ & $34(63)$ & 0.230 & $17(59)$ & 0.494 \\
\hline Norepinephrine, max dose, $\mu \mathrm{g} / \mathrm{kg} \mathrm{min}^{-1}$ & $0.3(0.2-0.6)$ & $0.5(0.3-0.7)$ & 0.123 & $0.4(0.3-0.5)$ & 0.500 \\
\hline ARDS & & & 0.698 & & 0.594 \\
\hline No & $30(88)$ & $47(87)$ & & $26(90)$ & \\
\hline Moderate & $3(9)$ & $3(6)$ & & $1(3)$ & \\
\hline Severe & $1(3)$ & $4(7)$ & & $2(7)$ & \\
\hline Creatinin $\max , \mu \mathrm{mol} \mathrm{I} \mathrm{I}^{-1}$ & $106(71-172)$ & $95(70-169)$ & 0.687 & $75(66-105)$ & 0.121 \\
\hline Score RIFLE & & & 0.902 & & 0.532 \\
\hline No renal aggression & $12(35)$ & $21(39)$ & & $15(52)$ & \\
\hline "Risk" & $7(21)$ & $11(20)$ & & $6(21)$ & \\
\hline "Injury" & $7(21)$ & $7(13)$ & & $3(10)$ & \\
\hline "Failure" & $8(23)$ & $14(26)$ & & $5(17)$ & \\
\hline "Loss" & $0(-)$ & $1(2)$ & & $0(-)$ & \\
\hline Extra renal support & $6(18)$ & $13(24)$ & 0.475 & $4(14))$ & 0.741 \\
\hline Mechanical ventilation & $28(82)$ & $43(79)$ & 0.753 & $25(86)$ & 0.741 \\
\hline Length of mechanical ventilation, days & $2(1-5)$ & $10(3-21)$ & 0.002 & $5(3-17)$ & 0.006 \\
\hline Sedation use & $23(68)$ & $40(74)$ & 0.515 & $21(72)$ & 0.681 \\
\hline Length of sedation, days & $1(1-3)$ & $3(2-6)$ & 0.002 & $1(1-4)$ & 0.095 \\
\hline Mean dose of midazolam, $\mathrm{mg} \mathrm{h}^{-1}$ & $1.2(1.0-1.5)$ & $1.3(0.9-1.6)$ & 0.793 & $1.2(0.9-1.5)$ & 0.902 \\
\hline Mean dose of morphine, $\mathrm{mg} \mathrm{h}^{-1}$ & $1.9(1.0-2.9)$ & $2.7(1.5-3.8)$ & 0.178 & $2.1(1.2-4.3)$ & 0.488 \\
\hline Use of neuro-blocking agent & $3(9)$ & $9(17)$ & 0.356 & $3(10)$ & 1.000 \\
\hline \multicolumn{6}{|l|}{ Rehabilitation $^{\dagger}$} \\
\hline Mobilization & $19(56)$ & $40(74)$ & 0.125 & $20(69)$ & 0.420 \\
\hline Out of bed & $15(44)$ & $31(57)$ & 0.319 & $19(65)$ & 0.148 \\
\hline Enteral nutrition & $26(77)$ & $46(85)$ & 0.302 & $26(90)$ & 0.170 \\
\hline \multicolumn{6}{|c|}{ Median daily dose of enteral nutrition delivered, $\mathrm{Kcal} / \mathrm{kg} \mathrm{day}^{-1}$} \\
\hline Between day 0 and day 5 & $8(5-12)$ & $11(7-15)$ & 0.050 & $11(6-16)$ & 0.151 \\
\hline Between day 6 and day 10 & $16(11-22)$ & $15(7-21)$ & 0.547 & $15(6-22)$ & 0.599 \\
\hline \multicolumn{6}{|c|}{ Median daily protein delivered via enteral nutrition, $\mathrm{g} / \mathrm{kg}$ day $^{-1}$} \\
\hline Between day 0 and day 5 & $0.3(0.2-0.5)$ & $0.5(0.3-0.6)$ & 0.025 & $0.5(0.2-0.6)$ & 0.064 \\
\hline Between day 6 and day 10 & $0.7(0.5-0.8)$ & $0.7(0.4-0.8)$ & 0.532 & $0.6(0.5-0.9)$ & 0.463 \\
\hline
\end{tabular}

Data are expressed as median (interquartile range 25-75) or number (percentage). *Non-frail vs frail or died at 6 months. ${ }^{* *}$ Non-frail vs frail at 6 months.

${ }^{\dagger}$ Mobilization and out of bed was notified as at least one action once during ICU stay. ARDS Acute respiratory distress syndrome, RIFLE risk, injury, failure, loss, end-stage renal disease, ICU intensive care unit

outcomes in ICU patients remains controversial, and no study has specifically addressed this issue in elderly ICU patients. A recent meta-analysis found that active mobilization and rehabilitation improved muscle strength and the probability of mobilization without assistance at hospital discharge but did not decrease ICU stay, hospital stay and 6-month mortality [31]. Another critical issue is the type of sedatives/opioids used for sedation/analgesia. Indeed, it has been shown that non-benzodiazepine-based sedation (dexmedetomidine or propofol) may reduce the length of ICU stay and duration of mechanical ventilation [32]. In the same way, remifentanil, a short half-life opioid, appeared to decrease the duration of mechanical ventilation, time to extubation and length of ICU stay [33]. Nevertheless, the impact of half-life sedatives and/or opioids does not appear to have any impact on mortality [32, 33]. In our institution, we used midazolam and morphine as sedative and analgesic agents. This point may have an impact on mechanical ventilation duration, but all our patients received the same agents according to a protocol. Moreover, the doses we used were low and did not differ between the groups.

Several limitations of our study need to be noted. First, it was monocentric, and our results may be difficult to 
Table 5 Length of stay, decision of withdrawal or withholding of life-sustaining therapies in ICU and mortality

\begin{tabular}{|c|c|c|c|c|c|}
\hline & $\begin{array}{l}\text { Robust at } \\
6 \text { months } \\
(n=34)\end{array}$ & $\begin{array}{l}\text { Frail or dead } \\
\text { at } 6 \text { months } \\
(n=54)\end{array}$ & $P^{*}$ & $\begin{array}{l}\text { Frail at } \\
6 \text { months } \\
(n=29)\end{array}$ & $p^{* *}$ \\
\hline \multicolumn{6}{|c|}{ Length of stay, days } \\
\hline ICU & $5(4-9)$ & $15(7-27)$ & $<0.001$ & $15(7-24)$ & $<0.001$ \\
\hline Hospital & $28(12-40)$ & $45(21-63)$ & 0.003 & $48(29-63)$ & $<0.001$ \\
\hline WWLST* in ICU & $0(-)$ & $17(31)$ & & $2(7)$ & \\
\hline \multicolumn{6}{|l|}{ Mortality } \\
\hline ICU & - & $13(24)$ & & - & \\
\hline Hospital & - & $18(33)$ & & - & \\
\hline At 6 months & - & $25(46)$ & & - & \\
\hline
\end{tabular}

Data are expressed as median (interquartile range 25-75) or number (percentage). *Non-frail vs frail or died at 6 months. ${ }^{* *}$ Non-frail vs frail at 6 months. ICU intensive care unit, WWLST withdrawal or withholding of life-sustaining therapies

generalize to other ICUs. Second, we chose to evaluate frailty by calculating an FI rather than using the clinical frailty scale (CFS), which is the most useful and widely used tool to evaluate frailty in the ICU [11]. Nevertheless, we used a validated frailty determination method that allowed us to explore and quantify each frailty domain and follow patients for 6 months, which would not be possible with the CFS. Third, we cannot exclude that patients had previous sarcopenia, which may have worsened muscle loss during ICU hospitalization. Indeed, it has been shown that sarcopenia at admission in older trauma patients, evaluated by the area of skeletal muscle on CT scan at the third lumbar vertebra, was associated with increased mortality (26\% vs $14 \%, p=$ 0.008 ) and independently associated with fewer ventilatorfree days and ICU-free days [34]. Accordingly, our patients were more frequently hospitalized within the 6 months prior to ICU admission, possibly favouring some degree of muscle loss, but this variable was not included in the multivariable analysis. Moreover, answers to items of the FI questionnaire specifically oriented to the evaluation of mobility and strength at admission were not altered in patients who remained non-frail and those who developed frailty (Additional file 2: Figure S1 and S2). Finally, we did not study precisely the level and lead time of physical/occupational therapy of patients during their ICU stay, which may differ between groups, but only if they had been mobilized and/or put out of bed at least once during their ICU stay.

\section{Conclusion}

Mechanical ventilation duration appeared to be a strong predictive factor of frailty and death or frailty alone 6 months after ICU hospitalization in patients who were non-frail at admission. Further studies should focus on the sequential evaluation of muscle loss in elderly patients in the ICU and evaluate the effect of early mobilization on the subsequent development of frailty in non-frail patients.

\section{Supplementary information}

Supplementary information accompanies this paper at https://doi.org/10. 1186/s40560-019-0403-3.

Additional file 1: Table S1. Details of the questionnaire for the calculation of the frailty index [from Searle SD, Mitnitski A, Gahbauer EA, Gill TM, Rockwood K. A standard procedure for creating a frailty index. BMC Geriatr. 2008;30:24]

Additional file $\mathbf{2}$ Details of the variables from the frailty index, reported at admission (remaining non-frail and becoming frail at 6 months) and at 6 months (patients remaining non-frail and becoming frail). Figure S1. Basic and instrumental daily living activities. Figure S2. Problems related to mobility and strength. Figure S3. Various feelings declared by the patients and trouble getting going. Figure S4. Weight loss, altered health status and problems with usual activities. Figure S5. Comorbidities.

\section{Abbreviations}

ARDS: Acute respiratory distress syndrome; CFS: Clinical frailty scale; Fl: Frailty index; ICU: Intensive care unit; RIFLE: Risk, injury, failure, loss, and end-stage renal failure; SAPS II: Severity acute physiologic assessment II;

SOFA: Sequential Organ Failure Assessment

\section{Acknowledgements}

None.

\section{Authors' contributions}

YL performed data analysis and developed the manuscript. HJ supervised the study, performed data analysis, and developed the manuscript. MA performed the data analysis and developed the manuscript. CR extracted the data and performed the statistical analysis and data analysis. NN performed the data analysis and developed the manuscript. PS conceived the study, supervised the study, performed the data analysis and developed the manuscript. All of the authors have read and approved the final manuscript.

\section{Funding}

None.

Availability of data and materials

Please contact the authors for data requests.

Ethics approval and consent to participate

The study was approved by the local institutional review board of the University of Rennes.

Consent for publication

Not applicable.

\section{Competing interests}

The authors declare that they have no competing interests.

\section{Author details}

${ }^{1} \mathrm{CHU}$ Rennes, Université Rennes 1, Service de Réanimation Chirurgicale, Hôpital Pontchaillou, 2 rue Henri Le Guilloux, 35033 Rennes Cedex 9, France. ${ }^{2} \mathrm{CHU}$ de Rennes, Centre d'Investigation Clinique, Inserm 1414, 2 rue Henri Le Guilloux, 35033 Rennes Cedex 9, France. ${ }^{3}$ Inserm, Institut NUMECAN UMR_A 1341, UMR_S 1241, F-35000 Rennes, France. ${ }^{4}$ Service d'Anesthésie Réanimation 1, Hôpital de Pontchaillou, 2 rue Henri Le Guilloux, 35033 Rennes Cedex 9, France.

Received: 8 April 2019 Accepted: 13 September 2019

Published online: 30 October 2019

\section{References}

1. Bagshaw SM, Webb SA, Delaney A, George C, Pilcher D, Hart GK, et al. Very old patients admitted to intensive care in Australia and New Zealand: a multicenter cohort analysis. Crit Care. 2009;13:R45. https://doi.org/10.1186/cc7768.

2. Ihra GC, Lehberger J, Hochrieser H, Bauer P, Schmutz R, Metnitz B, et al. Development of demographics and outcome of very old critically ill patients admitted to intensive care units. Intensive Care Med. 2012;38:6206. https://doi.org/10.1007/s00134-012-2474-7. 
3. Sjoding MW, Prescott HC, Wunsch H, Iwashyna TJ, Cooke CR. Longitudinal changes in ICU admissions among elderly patients in the United States. Crit Care Med. 2016;44:1353-60. https://doi.org/10.1097/CCM.0000000000001664.

4. Angus $D$. Admitting elderly patients to the intensive care unit-is it the right decision? JAMA. 2017;318:1443-4. https://doi.org/10.1001/jama.2017.14535.

5. Flaatten $\mathrm{H}$, de Lange DW, Artigas A, Bin D, Moreno R, Christensen S, et al. The status of intensive care medicine research and a future agenda for very old patients in the ICU. Intensive Care Med. 2017;43:1319-28. https://doi. org/10.1007/s00134-017-4718-z.

6. Clegg A, Young J, lliffe S, Rikkert MO, Rockwood K. Frailty in elderly people Lancet. 2013;381:752-62. https://doi.org/10.1016/S0140-6736(12)62167-9.

7. Le Maguet P, Roquilly A, Lasocki S, Asehnoune K, Carise E, Saint Martin M, et al. Prevalence and impact of frailty on mortality in elderly ICU patients: a prospective, multicenter, observational study. Intensive Care Med. 2014;40: 674-82. https://doi.org/10.1007/s00134-014-3253-4.

8. Bagshaw SM, Stelfox HT, McDermid RC, Rolfson DB, Tsuyuki RT, Baig N, et al. Association between frailty and short- and long-term outcomes among critically ill patients: a multicentre prospective cohort study. CMAJ. 2014;186: 95-102. https://doi.org/10.1503/cmaj.

9. Bagshaw SM, Stelfox HT, Johnson JA, McDermid RC, Rolfson DB, Tsuyuki RT, et al. Long-term association between frailty and health-related quality of life among survivors of critical illness: a prospective multicenter cohort study. Crit Care Med. 2015;43:973-82. https://doi.org/10.1097/CCM.0000000000000860

10. Heyland DK, Stelfox HT, Garland A, Cook D, Dodek P, Kutsogiannis J, et al. Predicting performance status 1 year after critical illness in patients 80 years or older: development of a multivariable clinical prediction model. Crit Care Med. 2016;44:1718-26. https://doi.org/10.1007/s00134-015-4028-2.

11. Muscedere J, Waters B, Varambally A, Bagshaw SM, Boyd JG, Maslove D, et al. The impact of frailty on intensive care unit outcomes: a systematic review and meta-analysis. Intensive Care Med. 2017:43:1105-22. https://doi. org/10.1007/s00134-017-4867-0.

12. Flaatten $H$, De Lange DW, Morandi A, Andersen FH, Artigas A, Bertolini G, et al. The impact of frailty on ICU and 30-day mortality and the level of care in very elderly patients ( $\geq 80$ years). Intensive Care Med. 2017:43:1820-8. https://doi.org/10.1007/s00134-017-4940-8.

13. Searle SD, Mitnitski A, Gahbauer EA, Gill TM, Rockwood K. A standard procedure for creating a frailty index. BMC Geriatr. 2008;30:24. https://doi. org/10.1186/1471-2318-8-24.

14. Le Gall JR, Lemeshow S, Saulnier F. A new simplified acute physiology score (SAPS II) based on a European/North American multicenter study. JAMA. 1993;270:2957-63. https://doi.org/10.1186/1471-2318-8-24.

15. Vincent JL, Moreno R, Takala J, Willatts S, De Mendonça A, Bruining H, et al. The SOFA (Sepsis-related Organ Failure Assessment) score to describe organ dysfunction/failure. On behalf of the Working Group on Sepsis- Related Problems of the European Society of Intensive Care Medicine. Intensive Care Med. 1996;22:707-10. https://doi.org/10.1007/bf01709751.

16. McCabe WR, Jackson GG. Gram-negative bacteremia. Arch Intern Med. 1962; 110:847-55.

17. Katz S, Down TD, Cash HR. Progress in the development of the index of ADL Gerontologist. Gerontologist. 1970;10:20-30. https://doi.org/10.1093/ geront/10.1_part_1.20.

18. Charlson ME, Pompei P, Ales KL, Mackenzie CR. A new method of classifying prognostic comorbidity in longitudinal studies: development and validation. J Chronic Dis. 1987;40:373-83. https://doi.org/10.1016/0021-9681(87)90171-8.

19. Definition Task Force ARDS, Ranieri VM, Rubenfeld GD, Thompson BT, Ferguson $N D$, Caldwell E, Fan E, et al. Acute respiratory distress syndrome: the Berlin Definition. JAMA. 2012;307:2526-33. https://doi.org/10.1001/jama.2012.5669.

20. Bellomo R, Ronco C, Kellum JA, Mehta RL, Palevsky P, the ADQI workgroup. Acute renal failure - definition, outcome measures, animal models, fluid therapy and information technology needs: the Second International Consensus Conference of the Acute Dialysis Quality Initiative (ADQI) Group. Crit Care. 2004;8:204-10. https://doi.org/10.1186/cc2872.

21. Berney SC, Harrold M, Webb SA, Seppelt I, Patman S, Thomas PJ, et al. Intensive care unit mobility practices in Australia and New Zealand: a point prevalence study. Crit Care Resusc. 2013;15:260-5.

22. Nydahl P, Ruhl AP, Bartoszek G, Dubb R, Filipovic S, Flohr HJ, et al. Early mobilization of mechanically ventilated patients: a 1-day point-prevalence study in Germany. Crit Care Med. 2014:42:1178-86. https://doi.org/10.1097/ CCM.0000000000000149.
23. Sibilla A, Nydahl P, Greco N, Mungo G, Ott N, Unger I, et al. Mobilization of mechanically ventilated patients in Switzerland. J Intensive Care Med. 2017: 1:885066617728486. https://doi.org/10.1177/0885066617728486.

24. Jolley SE, Moss M, Needham DM, Caldwell E, Morris PE, Miller RR, et al. Point prevalence study of mobilization practices for acute respiratory failure patients in the United States. Crit Care Med. 2017;45:205-15. https://doi.org/ 10.1097/CCM.00000000000002058.

25. Kortebein P, Ferrando A, Lombeida J, Wolfe R, Evans WJ. Effect of 10 days of bed rest on skeletal muscle in healthy older adults. JAMA. 2007;297:1772-4. https://doi.org/10.1001/jama.297.16.1772-b.

26. Pišot R, Marusic U, Biolo G, Mazzucco S, Lazzer S, Grassi B, et al. Greater loss in muscle mass and function but smaller metabolic alterations in older compared with younger men following 2 wk of bed rest and recovery. J Appl Physiol. 2016;120:922-9. https://doi.org/10.1152/japplphysiol.00858.2015.

27. Fan E, Dowdy DW, Colantuoni E, Mendez-Tellez PA, Sevransky JE, Shanholtz C, et al. Physical complications in acute lung injury survivors: a two-year longitudinal prospective study. Crit Care Med. 2014;42:849-59. https://doi. org/10.1097/CCM.0000000000000040.

28. Needham DM, Wozniak AW, Hough CL, Morris PE, Dinglas VD, Jackson JC, et al. Risk factors for physical impairment after acute lung injury in a national, multicenter study. Am J Respir Crit Care Med. 2014;189:1214-24. https://doi.org/10.1164/rccm.201401-01580C.

29. Latronico N, Herridge M, Hopkins RO, Angus D, Hart N, Hermans G, et al. The ICM research agenda on intensive care unit-acquired weakness. Intensive Care Med. 2017;43:1270-81. https:/doi.org/10.1007/s00134-017-4757-5.

30. Schweickert WD, Pohlman MC, Pohlman AS, Nigos C, Pawlik AJ, Esbrook CL, et al. Early physical and occupational therapy in mechanically ventilated, critically ill patients: a randomised controlled trial. Lancet. 2009;373:1874-82. https://doi.org/10.1016/S0140-6736(09)60658-9.

31. Tipping CJ, Harrold M, Holland A, Romero L, Nisbet T, Hodgson CL. The effects of active mobilisation and rehabilitation in ICU on mortality and function: a systematic review. Intensive Care Med. 2017;43:171-83. https:// doi.org/10.1007/s00134-016-4612-0.

32. Zhu Y, Wang Y, Du B, Xi X. Could remifentanil reduce duration of mechanical ventilation in comparison with other opioids for mechanically ventilated patients? A systematic review and meta-analysis. Crit Care. 2017; 21:206. https://doi.org/10.1186/s13054-017-1789-8.

33. Fraser GL, Devlin JW, Worby CP, Alhazzani W, Barr J, Dasta JF, et al. Benzodiazepine versus nonbenzodiazepine-based sedation for mechanically ventilated, critically ill adults: a systematic review and meta-analysis of randomized trials. Crit Care Med. 2013;41(Suppl 1):30-8. https://doi.org/10. 1097/CCM.0b013e3182a16898.

34. Moisey LL, Mourtzakis M, Cotton BA, Premji T, Heyland DK, Wade CE, et al. Nutrition and Rehabilitation Investigators Consortium (NUTRIC). Skeletal muscle predicts ventilator-free days, ICU-free days, and mortality in elderly ICU patients. Crit Care. 2013;17:R206. https://doi.org/10.1186/cc12901.

\section{Publisher's Note}

Springer Nature remains neutral with regard to jurisdictional claims in published maps and institutional affiliations.

Ready to submit your research? Choose BMC and benefit from:

- fast, convenient online submission

- thorough peer review by experienced researchers in your field

- rapid publication on acceptance

- support for research data, including large and complex data types

- gold Open Access which fosters wider collaboration and increased citations

- maximum visibility for your research: over $100 \mathrm{M}$ website views per year

At $\mathrm{BMC}$, research is always in progress.

Learn more biomedcentral.com/submissions 